\title{
Lao separation verbs and the logic of linguistic event categorization
}

\author{
N. J. ENFIELD*
}

\section{Abstract}

While there are infinite conceivable events of material separation, those actually encoded in the conventions of a given language's verb semantics number only a few. Furthermore, there appear to be crosslinguistic parallels in the native verbal analysis of this conceptual domain. What are the operative distinctions, and why these? This article analyses a key subset of the bivalent (transitive) verbs of cutting and breaking in Lao. I present a decompositional analysis of the verbs glossed 'cut (off)', 'cut.into.with. placed.blade', 'cut.into.with.moving.blade', and 'snap', pursuing the idea that the attested combinations of sub-events have a natural logic to them. Consideration of the nature of linguistic categories, as distinct from categories in general, suggests that the attested distinctions must have ethnographic and social interactional significance, raising new lines of research for cognitive semantics.

Keywords: cut and break; separation events; Lao; verb semantics; linguistic categorization; natural logic; interaction.

\section{Introduction}

Meanings of event-denoting expressions like 'cut', 'chop', and 'snap' may in part be shaped by the perceptual cues which define points of salience and discontinuity in commonly encountered action types. Perhaps more importantly, each such word encodes or taps a conceptual rationale, a locally and culturally defined purpose behind a conceived actor's goal in selecting one or another action type, and a logic to the particular combination of sub-events each term specifies. I explore this with reference to verbs of material separation in Lao, an isolating/analytic language of Laos, Thailand, and Cambodia (see Enfield forthc.). The analysis draws 
in part on results of elicitation using a video stimulus set, as described in the introduction to this special issue (Majid et al., this issue). The full set was explored with three consultants, all native to the Vientiane area. Further discussion of the semantics of verbs in this domain were conducted with these consultants, and complemented with observation based on field work and other ongoing experience with the language since 1988.

\section{Conceived events of separation}

Humans bring finite conceptual order to an infinity of possible real events, thanks to our stock of resources for interpretive categorization. Perhaps most salient among these resources are the semantic categories of natural languages. In analyzing complex event semantics, traditions in research on verb meaning have successfully used reductive logical configurations of simple conceptual components (e.g., Dowty 1979; Jackendoff 2002; Wierzbicka 1996). My analysis of Lao verb semantics in the domain of caused material separation, or "cutting and breaking", employs the following components:

Table 1. Some key conceptual elements of conceived complex events of material separation

\begin{tabular}{|c|c|}
\hline$A$ & actor \\
\hline$U$ & undergoer \\
\hline Instr & instrument \\
\hline$p$ & $\begin{array}{l}\text { A does something to } \mathrm{U} \text {, using instrument, touching } \mathrm{U} \text { at some location/part } \\
\text { (LOCp) }\end{array}$ \\
\hline$q$ & $\begin{array}{l}U \text { undergoes some change of state at LOCq involving material separation } \\
\text { (i.e. in which part or all of } U \text { goes from being one to being not one) }\end{array}$ \\
\hline$\rightarrow$ & There is a relationship of cause $(\rightarrow)$ between $p$ and $q$ \\
\hline INT & $\begin{array}{l}\text { A has an intentional state with regard to } q \text { (A may or may not know that } p \\
\text { will result in } q \text {; may or may not want } p \text { to result in } q \text {; may or may not } \\
\text { know precisely when or where } q \text { will happen) }\end{array}$ \\
\hline$T p / q$ & $\begin{array}{l}\text { temporal specifications distinct for } p \text { and } q \text { : the time } \mathrm{U} \text { is touched/affected } \\
\text { at } p \text { may or may not be the same as the time } \mathrm{U} \text { is touched/affected at } q \text {. } \\
\text { (Internal temporal structure of } p \text { and } q \text { may vary, being either } \\
\text { momentaneous or temporally extended.) }\end{array}$ \\
\hline$L O C p / q$ & $\begin{array}{l}\text { location of touch/effect for } p \text { and } q \text { : these may or may not be the same } \\
\text { location. }\end{array}$ \\
\hline
\end{tabular}

The values presented in Table 1 may be varied to capture the underlying structure of distinctions such as 'cut' versus 'chop' versus 'snap' (see below). Beyond these basic parameters of variation, the complex semantics of separation verbs will further differ in terms of precisely what 
constitutes the $p$ action (e.g., causing a heavy instrument to move and impact upon $\mathrm{U}$; pushing a blade into $\mathrm{U}$; pushing a hand down onto the centre of U). The verbs' meanings may also be abstract to varying degrees, leaving variables unspecified. Given even this small number of logical components, a set of values as in Table 1 will generate a virtually indefinite number of distinctions between conceivable types of separation events. In natural language, however, we don't see indefinite variation. A finding of this special issue is that from this vast if not infinite search space, the set of complex event types denoted by particular verbs in particular languages will be not only finite but small.

\section{Lao material separation verbs}

Lao stocks a few dozen verbs of separation, mostly bivalent/transitive. Only a handful are strictly monovalent/intransitive, including tèek5 'break/broken' and khaat5 'torn/severed' (numerals in transcription of Lao words represent lexical tone). The monovalent verbs cover a wide range of separation situations. Tèè 5 'break', for example, covers glass breaking, hair splitting, skin cracking, and more, so long as (a) there is some separation in the material integrity of the entity (i.e., where it was "one" and is now no longer; Goddard 1998: 281), and (b) the separation has not been directly caused by something going in (e.g., a knife). For khaat5 'torn/severed', the locus of separation is typically twodimensional and soft/flexible (e.g., cloth or paper). The monovalent verbs are pre-empted by bivalent verbs when an agent is involved. They will often appear as resultative verbs in multi-verb sequences depicting transitive separation events (Enfield forthc.; cf. Chen, this issue). For example, the sequence thup1 caan 3 tèek5 (do.smashing.action.on plate break) 'smash a plate' was used to describe a stimulus clip in which an actor smashes a plate with a hammer. Both tèek5 'break' and khaat5 'torn, severed' are common in this resultative complement function, along with directional verbs such as qòok5 'off, apart, out, exit'. The complexities of argument structure arising from these complex predications are beyond the scope of this paper. I focus instead on semantic distinctions among the bivalent separation verbs tat 2 'cut (off)', paat5 'cut.into.with. placed.blade', fan 2 'cut.into.with.moving.blade', and hak2 'snap'. Given limited space, these four are selected to represent key contrasts (articulated in terms of the distinctions introduced in Table 1), and to illustrate the claim that verbal semantic structure contains not only specifications of perceivable actions/events and sub-actions/events, but a rationale for how and why those sub-events interlock. 


\subsection{Four bivalent Lao verbs of separation}

3.1.1. Tat2 'cut (off)'. Tat2 is translated into English as 'cut' or 'cut off' (Kerr 1972: 600), though it is equal in meaning to neither. Its meaning is more general than those of the other verbs described below. Tat2 covers scenes as varied as cutting meat with a knife, segmenting rice cakes with string, cutting paper with scissors, cutting down a tree with an axe, cutting grass with a lawnmower, or cutting a fish in half by placing a knife on it and hammering it in. Like other verbs discussed below, tat 2 entails the presence of an instrument, but here the only constraint is that the instrument be able to penetrate $\mathrm{U}$ in some way (wire would do). Tat2 is more general than the other verbs in that it encodes no specific information about manner of initial causing action $p$, temporal relations between $p$ and $q$, or internal temporal structure of $p$ and/or $q$. To be precise, A tat $2 \mathrm{U}$ means A does something $p$ to $\mathrm{U}$ with Instr, causing Instr to go into $\mathrm{U}$, causing part of $\mathrm{U}$ to be separated completely from the whole at the point of separation. The requirement that Instr must enter $U$ accounts for the inapplicability of this verb to a scene in which an actor divides a carrot by hitting the centre of it with a hammer, crushing it and causing it to come apart in two pieces. The requirement that part of $U$ must be separated completely from the whole rules out a scene in which an actor makes a cut in a melon, but without causing any part of the melon to be separated off. Speakers exclusively chose tat 2 to describe scenes involving the canonical use of scissors. As is discussed in more detail below (see Figure 1), the relative semantic generality of tat2 'cut (off)' means that it may describe many scenes also describable by the more manner-specific separation verbs to which we now turn.

\subsubsection{Paat5 'cut.into.with.placed.blade'. Kerr (1972: 799) approximates} the meaning of paat5 with English 'slice', 'cut', and 'cut open'. More precisely, A paat $5 \mathrm{U}$ means A does something $p$ to $\mathrm{U}$, using a bladed instrument (that is, a hard flat piece with a long sharp edge), first placing the blade on $U$ at the desired place of separation, then pressing the blade onto $\mathrm{U}$ and moving it along or down onto its blade axis. This causes Instr to go into $\mathrm{U}$, causing $\mathrm{U}$ to separate where and when $\mathrm{A}$ puts pressure on it. The place of separation is only where Instr touches U. Thus, paat5 describes highly controlled separation. That is, the separation event $q$ happens where and when the causing event $p$ happens (not at some other place or time), because that's where and when A intends it to happen. So, if a cut is brought about with a non-controlled action, paat 5 is not applicable. ${ }^{1}$ That Instr is placed on $\mathrm{U}$ prior to applying force correctly predicts applicability to canonical cutting scenes like slicing a fish into 
pieces, and not to scenes in which a blade is not first placed (e.g., chopping carrots with a machete). That the force of the cutting action should come from A consistently pushing Instr into $U$ from one side excludes scenes featuring the canonical use of scissors. It also excludes scenes in which A first places a non-entering instrument like a hammer on the place of intended separation and then pushes down, causing separation by crushing the centre of U. Unlike tat2 'cut (off)', paat5 does not require (but does not preclude) full separation of part of U. Accordingly, making an incision in a watermelon is described with paat5, never with tat2 'cut (off)'.

\subsubsection{Fan2 'cut.into.with.moving.blade'. Fan2 is like chop: A does} something $p$ to $\mathrm{U}$, using a heavy and rigid instrument, grasping and moving it through the air so that it comes into contact with U quickly and forcefully. This action is done intending that it cause Instr to go into $\mathrm{U}$ at or near a certain point and cause $U$ to separate there. These scenes feature a lower degree of control by A than those describable by paat 5 'cut.into.with.placed.blade', for two reasons. First, separation is less likely to occur exactly where A intends it because Instr is moving when it comes into contact with U. Second, since Instr's contact with U involves some force, this means that separation may occur not only where Instr touches $\mathrm{U}$, but also adjacent to that point. The specifications 'Instr is moving upon contact' and 'Instr enters $\mathrm{U}$ upon contact' predict the use of fan2 for, say, halving a watermelon by swinging a machete down onto it. These same specifications also rule out cases in which Instr is not moving upon contact (e.g., first placed, then pushed in), or where separation is not caused by entry of Instr (e.g., bringing a hammer down onto a carrot, crushing it, and so causing it to divide). ${ }^{2}$

\subsubsection{Hak2 'snap'. Hak2 'snap' was the only verb chosen to describe a} set of four scenes among the stimuli whose common properties are: A intentionally does something to a long and rigid U, causing it to bend, prolonging this over time until this causes $U$ to separate (into two pieces) at a given moment. This covers typical snapping scenes in the stimulus set like snapping a stick over the knee, as well as culturally common scenes like snapping the spine of a half-eaten fish by lifting it at one end, or snapping a stick of celery. A's intentional state differs from those encoded or implied in the verb meanings discussed above: here, while A acts with the intention to cause separation, A doesn't know exactly when separation will occur (Tq); and as in fan 2 scenes, but not as in tat 2 or paat 5 scenes, A doesn't know exactly where separation will occur (LOcq). With hak2 
this is because the precise place of separation (LOCq) is not determined by something touching $U$ at that place. That is, LOcp and Locq are distinct. ${ }^{3}$ Temporally, as in fan 2 scenes, the $p$ phase of a hak2 scene is both prior to $q$ and extended over time. In this sense, hak 2 is like fan2, but the causing action in hak2 scenes - unlike fan 2 scenes - is not ballistic (that is, $p$ can be abandoned any time without $\mathrm{A}$ being committed to its final effect).

3.1.5. Summary. Analysis of these four common verbs of separation illustrates key distinctions in this domain conventionally made in Lao, expressed in terms of the conceptual components in Table 1. We now consider system-level relations among these and related verbs, before further considering the rationale(s) for their internal semantic structure.

\section{Structure of the system of Lao bivalent separation verbs}

There are two main levels of semantic generality within the bivalent verbs. At a generic level are everyday verbs whose extensions are exclusive regions of the semantic space derived from the logical components given in Table 1. These include the verbs discussed already (except tat2; see below), along with other verbs elicited by the stimulus scenes (e.g. phaal 'split', ciik5 'tear', lùajl 'saw'). These verbs each specify a distinct manner of causing action, and accordingly, they do not describe the same scenes. At a specific level are semantically narrower verbs whose referential range is subsumed entirely by that of a generic verb. Thus, any event described by cak2 'split length of bamboo/rattan along grain' can also be described by generic phaal 'split', but not vice versa. Ditto for specific biq2 'snap using fingertips' and bit2 'snap by twisting', both subsumed by generic hak2 'snap'.

One verb-tat2 'cut (off)'-differs in semantic generality from other generic verbs, but does not occupy a separate hierarchical level. Tat2 is less specific in some respects and more specific in others. It is less specific about details of the causing action $p$, specifying only that some penetrating instrument is used, but without further coding of type of instrument or manner of action. The action need only involve entry of instrument (knife, wire, scissors, axe, etc.) into U. On the other hand, tat2 is MORE specific about the RESULTING action $q$, specifying that some part of $\mathrm{U}$ becomes fully detached. The extension of tat2 'cut (off)' overlaps with paat 5 'cut.into.with.placed.blade' and fan2 'cut.into.with.moving.blade', since these are unspecified for 'separation from whole'. None subsumes the others: 


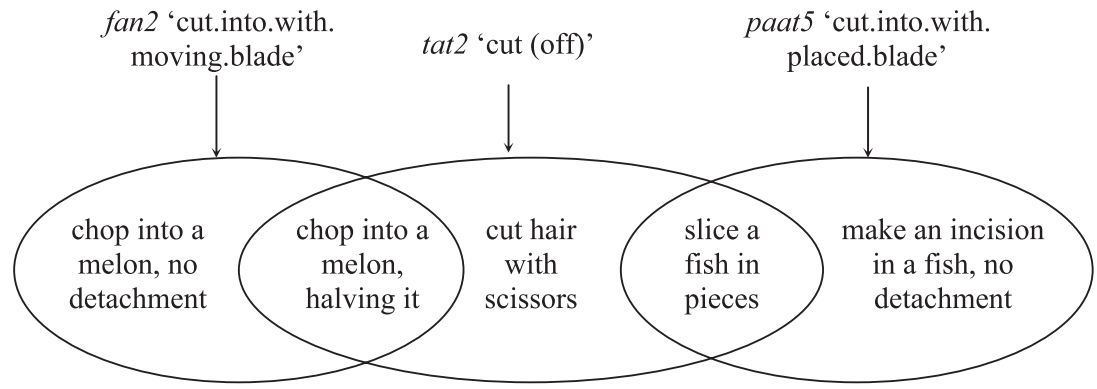

Figure 1. Overlapping distribution of three generic verbs for sample $C \& B$ scenes.

\section{Discussion: Implications for cognitive semantics}

Given the normally dramatic variation in semantic structure across languages (Goddard 2001), it is perhaps surprising that the conceptual distinctions made by Lao separation verbs pattern fairly consistently with those of other languages (see introduction to this issue; Majid et al., this issue). What could explain this? One possibility is that linguistic categories are shaped by the human perceptual apparatus, hence universally similar. For Berlin (1992: 8), convergence in linguistic categorization of the biological world is due to "human beings' inescapable and largely unconscious appreciation of the inherent structure of biological reality." Berlin argues that this appreciation is perceptually given along with Nature's Plan. While the Lao data may indeed support a hypothesis of inherent structure in the reality of separation events, I submit that this structure is not delivered by perceptual discontinuities alone. If there is inescapable and unconscious appreciation of structure in this domain of reality, it is not only shaped by perception (or perceptual cognition), but also reflects an analysis of these events' natural logic. By this I do not mean a mere co-occurrence of features. What matters are the purposive and rational connections among the components of a conceived complex event that tell us why just those features go together in the way they do (cf. Kockelman 2006). No such connections will explain the cooccurrence of beaks, feathers, and wings.

Consider the rationale for a moving instrument component in the meaning of fan 2 'cut.into.with.moving.blade': the need for extra power. If I need to separate bone, I do not have the strength to do it if I first place the blade and then push down/along (as might work with meat or fish). There is a trade-off between power and precision. Having the blade in motion affords greater force upon contact. But a natural consequence is lower accuracy. This is because the blade may come into contact with 
$\mathrm{U}$ at a place not exactly where I intended it, and this ballistic placement cannot be adjusted at the last moment. Also, there may be collateral damage beyond the point of contact (e.g., cracking in the case of bone). Consider the differences between paat5 and fan2: for paat5, force is applied after the blade is in contact with the undergoer, separation is clean and accurate, caused by pushing; for fan2, force is applied to the blade BEFORE contact, separation is not clean and accurate, but separation may be effected with more resistant undergoers. These differences arise from natural relations among the ensembles of features they respectively denote. Each verb describes an event complex in which just that combination of sub-events is logically motivated.

Can we draw conclusions here about the general nature of linguistic categorization? Not yet. An appreciation for a given category distinction might explain why a concept is widespread in the minds of a community's members, but it does not explain why a concept is publicly labelled. Without telepathy, only signifiers (i.e., words), not signifieds (i.e., concepts), are literally made public. These signifiers remain no more than "lures for cognition" (Brown 1958: 206), public invitations from speaker to recipient to activate or compose fitting signifieds, i.e., concepts sufficiently similar for current purposes to those concepts a speaker intends to communicate. Even the best motivated conceptual category is not a LINGUISTIC category unless there is a community-wide practice of using a conventional phonological label to denote it in communicative interaction. The existence of a convention of using the word presupposes its prior historical social diffusion (Enfield 2005: 194-197), which in turn presupposes the word's utility as a device for solving recurrent problems of social coordination (Clark 1996; Evans 2003; Lewis 1969; Schelling 1960; Simpson 2002). The logical structure of a verb's conceptual content may directly map onto culturally and socially significant activity/goal structures (e.g., in food preparation, paat 5 is fitted to preparing meat, fan 2 to dealing with bone). It is hardly surprising, given the typically collaborative/communal nature of food preparation, that categories like fan2 'cut.into.with. moving.blade' and paat5 'cut.into.with.placed.blade' have been historically useful in Lao-speaking communities as devices for coordination of joint activity.

So, if the word serves primarily as a social coordination device (Wittgenstein 1953), and only secondarily as a conceptual fixative (Vygotsky 1934), the question is not (only) how linguistic categories function to organize thoughts, or to display the organization of thoughts, but (also) how they function to organize social interaction (Sacks 1992). Cognitive semantic studies like the present one have yet to deal with this critical issue. For verbs of material separation, as for any linguistic category, truly 
figuring them out will require an ethnographically grounded understanding of the social purposes for which communities collectively maintain the semiotic distinctions they maintain.

Received 14 June 2005

Revision received 7 September 2006
Max Planck Institute for

Psycholinguistics, Nijmegen, The Netherlands

\section{Notes}

* Max Planck Institute for Psycholinguistics, Postbus 310, 6500 AH, The Netherlands; Email: 〈Nick.Enfield@mpi.nl〉. This work is supported by the Max Planck Society. I gratefully acknowledge careful and critical commentary in conversation and correspondence with Asifa Majid, Melissa Bowerman, David Wilkins, Cliff Goddard, and Anna Wierzbicka.

1. But note that there is some slippage: one may accidentally paat5 one's finger, but only when otherwise rightfully doing a paat 5 action, e.g. in food preparation. The same is true, mutatis mutandis, for fan 2 and hak2, below.

2. The bivalent/transitive term thupl, loosely translatable as 'smash', similarly specifies that the instrument is moving upon contact, but it differs from fan2 in that the part of instrument which makes contact with $U$ should be a broad surface, not the sharp edge of a blade. With thupl 'smash', the instrument does not divide $\mathrm{U}$ by entering it. Instead, its heavy impact causes $U$ to separate into many pieces.

3. While a snapping scene may involve contact between instrument and Locq (e.g. when snapping a stick over the knee), separation here is no more due to contact at LOCq than it is to the hands' contact at each end of the stick (included in LOcq; this contact at each end of $U$ is crucially required for the knee action to result in separation where and how it does).

\section{References}

Berlin, Brent

1992 Ethnobiological Classification. Princeton: Princeton University Press.

Brown, Roger

$1958 \quad$ Words and Things. Glencoe: The Free Press.

Chen, Jidong

this issue 'He cut-break the rope': Encoding and categorizing cutting and breaking events in Mandarin. Cognitive Linguistics 18(2), 273-285.

Clark, Herbert H.

1996 Using Language. Cambridge: Cambridge University Press.

Dowty, David R.

1979 Word Meaning and Montague Grammar. Dordrecht: Kluwer Academic Publishers.

Enfield, N. J.

2005 Areal linguistics and Mainland Southeast Asia. Annual Review of Anthropology 34, 181-206.

forthc. A Grammar of Lao. Berlin/New York: Mouton de Gruyter. 
Evans, Nicholas D.

2003 Context, culture, and structuration in the languages of Australia. Annual Review of Anthropology 32, 13-40.

Goddard, Cliff

1998 Semantic Analysis. Oxford: Oxford University Press.

2001 Lexico-semantic universals: A critical overview. Linguistic Typology 5, 1-65.

Jackendoff, Ray

2002 Foundations of Language. Oxford: Oxford University Press.

Kerr, Alan D.

1972 Lao-English Dictionary. Washington: Catholic University of America Press.

Kockelman, Paul

2006 Residence in the world: Affordances, instruments, actions, roles, and identities. Semiotica 162, 19-71.

Lewis, D. K.

1969 Convention: A Philosophical Study. Cambridge: Harvard University Press.

Majid, Asifa, Melissa Bowerman, Miriam van Staden, and James S. Boster

this issue The semantic categories of cutting and breaking events: A crosslinguistic

Sacks, Harvey

perspective. Cognitive Linguistics 18(2), 133-152.

1992 Lectures on Conversation. London: Blackwell.

Schelling, Thomas C.

1960 The Strategy of Conflict. Cambridge: Harvard University Press.

Simpson, Jane

2002 From common ground to syntactic construction: Associated path in Warlpiri. In Enfield, N. J. (ed.), Ethnosyntax. Oxford: Oxford University Press, 287-308.

Vygotsky, Lev

$1934 \quad$ Thought and Language. Cambridge, MA: MIT Press.

Wierzbicka, Anna

1996 Semantics: Primes and Universals. Oxford: Oxford University Press.

Wittgenstein, Ludwig

$1953 \quad$ Philosophical Investigations. Oxford: Blackwell. 